\title{
Soil Protection in the Amhara National Regional State: The Legal and Practical Assessment
}

\author{
Sibuh Gebeyaw Tareke \\ Department of Land and Environmental Law, Bahir Dar University, Bahir Dar, Ethiopia
}

\begin{abstract}
In the highland areas of Ethiopia, rainfall is more intense and soils are highly erodible due to the relatively shallow depth and low structural stability. The Amhara region, being one part of the highland areas of a country, loss high amount of yield as a result of loss of topsoil each year is increasing substantially. This makes the government due attention to its development and environmental policy on the issue of soil conservation not only necessary, but also a vital concern if the country wants to achieve sustainable development of its agricultural sector and its economy at large. To curb this problem, efforts towards the soil protection were started a decade before. Accordingly, various theoretical and empirical models of soil conservation decisions have been developed be it at the regional, local and farm household level. Thus, in some recent Years, the regional government becomes highly motivated to mobilize the public at large and some effective soil conservation activities have been achieved. However, the efforts put towards the promotion of the conservation technologies so far seem to have a little success in achieving sustained use and widespread adoption. This makes the main purpose of this study is, thus, how the law in the book and the law in practice associated with adoption of introduced soil conserving practices and draw conclusions that contribute in the future improvement of the design and implementation of protection programs.

Keywords: - Soil Erosion; Soil Ptotection; Community Participation; Watershed Development and Amhara Region
\end{abstract}

DOI: $10.7176 / \mathrm{JEES} / 10-2-02$

Publication date: February $29^{\text {th }} 2020$

\section{Introduction}

The environment is the most valuable resource. It is the foundation of the materials we require both to survive and to take our lives for a better standard of living (Dessalegne, 2007). A productive and healthy environment provides us to build a sustainable development, technological advancement to produce goods and services sufficient for this purpose. We draw from it directly into our food, shelter, medicine, raw materials for making products, etc. (Ibid, 2007).

Because of inappropriate use and over exploitation, throughout the world today, depletion of natural resources is among the major problems facing human beings. Among others, soil erosion is one of the biggest global environmental problems, resulting in both on-site and off-site effects (Abate, 2011). Soil erosion has accelerated in most parts of the world, especially in developing countries, due to different socioeconomic and demographic factors that is an increasing population; deforestation, intensive land cultivation, uncontrolled grazing and higher demand for firewood often cause soil erosion (Ibid, 2011).

According to the Federal Democratic Republic of Ethiopia/ FDRE Ministry of Agriculture and Rural Development/ MARD (2005), the Ethiopian economy is primarily agricultural. In any single year, agricultural production makes up more than 40 percent of the GDP. Much of the foreign currency earnings are derived from it and some 85 percent of the country's population derives their livelihood directly from the sector. The average annual rate of soil loss in Ethiopia is estimated to be 12 tons/hectare/year, and it can be even higher on steep slopes with soil loss rates greater than 300 tons/hectare/year or $250 \mathrm{~mm} /$ year, where vegetation cover is scant (Ministry of Agriculture and Rural Development, 2005).

Similarly, the Amhara region depends on agricultural products, despite its role, the sector is characterized by low productivity and high exposure to risk due to adversely varying environmental conditions (Abera, 2003). The ecological discrepancy the region is facing today presents a serious challenge. Annual agricultural production cannot keep pace with the growing number of the population and this exposed, especially the eastern part of the region's agricultural population to food insecurity (Ibid, 2003).

This has led to a continuous fragmentation of land holdings. For instance, reductions in soil fertility and crop yield may encourage behaviors that intensify production, such as shortening of fallows, adoption of new crops and technologies (Gizaw and Hurni, 2011). Thus, soil is over eroded and its productive capability is diminished. Especially it is a very severe problem in the region on cultivated lands. The problems of population increase on the one hand and the limited availability of arable land coupled with severe soil depletion on the other, makes strengthening of agricultural production while maintaining the resource base urges (Ibid, 2011).

In recent years, the regional government has established soil conservation rules and proclamations to resolve this problem. The mechanism to conserve soil resources and prevent degradation is through public participation, have been involved in addressing the widespread problem of land degradation. The conservation measures were 
in most of the cases, physical structures, namely stone or soil bunds. The conservation works have been carried out through the campaign (Morgan, 2005). But the problem is not as such solved as it was expected because of the limitations of the government to implement the established laws and regulations as well as lack of clear and continuous trainings on the parts of experts and the community at large(Ibid).

Therefore, this study attempts to assess the sustainable use of physical conservation measures introduced through a major soil protection program. A better knowledge of, how the characteristics of the individual farmers and the community practices affect conservation investments; how the problem is worth the attention of policy makers in designing more effective conservation programs and assuming the research findings lead to some useful change in best practice as well as to set up the best soil protection mechanisms.

The research method used is a qualitative research and both primary and secondary data will be employed. The primary source, includes; interviews and relevant proclamations. Secondary source, includes different text books, reports, and related sources will be employed. The instruments and strategies for collecting data included semi-interviews with questions wording can be changed and explanations given. The questions were designed to meet the objectives of the study. It was designed to regional Bureau of Agriculture /BoA and Bureau of Environmental Protection Land Administration and Use/ BoEPLAU. The discussion was undertaken intentionally with 1 leaders and 3 selected experts working in both sectors. The data analysis is that the researcher should derive his explanations of the phenomenon in question by looking closely at the empirical data that have been collected.

\section{Historical Factors Related to Soils Problems and Protective Mechanisms \\ 2.1. Empirics of Soil Problems}

Throughout the world today, the demand for increased environmental services and goods has remained very high. Massive resource use has caused loss of environmental resources in many ecosystems and has jeopardized present and future livelihoods. In particular, introduction of destructive practices and technologies have increased environmental degradation and led to deterioration of the quality of soil (Dessalegne, 2007).Agricultural activities generated to mine the soil the way minerals are mined. Worldwide inappropriate agricultural practices account for 28 percent of the degraded soil. About one fourth of them are found in Africa and Asia and nearly two thirds of the degraded soil are in North America (Abay, 2011).

The most frequently cited causes include continuous cropping with short or no fallowing triggered by high population pressure, over cultivation and marginal lands without adequate erosion-controlling measures, insufficient drainage of irrigation water and deforestation. Similarly, Overgrazing by livestock population is also another factor that led to soil erosion. Estimates identified that overgrazing account for nearly half of all land degradation in Africa (Abera, 2003).

Agricultural producers, as well as managers of nonagricultural lands, need to know what to expect in terms of soil erosion by wind and water resulting from alternative management practices (Edward, 1987). According to Edward:-

Erosion of soil by wind is a particularly serious problem in many arid and semiarid regions. Arid lands contained about one-third of the world's total land area and are the home of one-sixth of the world's population. Areas under agricultural production that are most susceptible to wind erosion include much of North Africa and the Near East, parts of Southern and Eastern Asia, the Siberian plains, Australia, Southern part of South America, and the semiarid and arid portions of North America.The Sahelian region of West Africa has seen dramatic changes over the past few decades, with decreasing rainfall, vegetation, and wildlife, and increasing wind erosion on the southern fringes of the Sahara desert (Ibid, 1987).

Similarly, on a world scale, investigations of the relationship between soil loss and climate show that at annual precipitation totals below $450 \mathrm{~mm}$, erosion increases as precipitation increases. But as precipitation increases so does the vegetation cover, resulting in better protection of the soil surface, so that for annual precipitation between 450 and $650 \mathrm{~mm}$, soil loss decreases as precipitation increases (Hurni, 1986).

Theoretically, whether or not a rate of soil loss is severe may be judged relative to the rate of soil formation. If soil properties such as nutrient status, texture and thickness remain unchanged through time, it can usually be assumed that the rate of erosion balances the rate of soil formation (Ibid, 1986). According to United Nation Environmental Program /UNEP, human impacts on the natural resources have entailed growing concerns:Atmosphere, soil and water resources are spoilt. Persistent organic pollutants and toxic substances have accumulated in living organisms. Species have been lost and ecosystems are being degraded. Social and ecological systems are being subjected to natural and anthropogenic hazards and catastrophes. Overall, human beings' activities have reached a scale where they are entailing severe impact on natural resources (Bekele, 1998). 


\subsection{The Development of Soil Protection Mechanism}

Protection and care of environmental recourses were not something that started in the $21^{\text {st }}$ Century. All the major religions have always affirmed respecting for nature. Noah is said to have undertaken the demanding task of saving representatives of all creatures in his ark during the deluge. This has served as an example to undertake ex situ conservation of species at times of crisis. One of the principles of Islam is that God's wisdom has bequeathed the Earth to Man and thus has to keep, maintain and preserve it in its integrity (Dessalegne, 2007).

Even though the protection started in ancient time, responses to the natural resources crisis highly considered after Stockholm conference 1972.The establishment United Nation Conference on Environment and Development/ UNCED, paying attention to the global environmental problem. UNCED report also emphasized on the social and economic dimensions of sustainability, revealing the link between, for example, poverty and natural resources degradation (Philippe, 2003). The UNCED was the unique occasion when the world acknowledged importance of sustainable development and reached consensus on addressing major natural resources (water, soil, air, forest, etc.) issues. One of the documents from the Earth Summit that is commonly known as "Agenda 21" was unanimously adopted as a blueprint for action throughout the $21^{\text {st }}$ Century. Since then worldwide acceptance of environmental issues has been growing and Multilateral Environmental Agreement/ MEAs, have been issued in the context of sustainable development (Ibid, 2003).

Again in developing countries, it became into an integral manner during the last few years, there has been considerable discussion concerning the soil problem in African dry lands and the management of its nutrients. The rationale of responding to this problem is thus based on the thinking that it plays a vital role in building diversified economy (Tor, 1997).

Soil protection can be masked by technological advances, e.g., using improved cultivars, chemicals, and soilcrop management practices. Sound soil management is thus the most important factor that counteracts erosioninduced changes in soil quality through appropriate systems of soil and crop management (International Atomic Energy Agency, 2001). It follows that the strategies for soil conservation must be based on: covering the soil to protect it from raindrop impact; increasing the infiltration capacity of the soil to reduce runoff; improving the aggregate stability of the soil; and increasing surface roughness to reduce the velocity of runoff and wind (Ibid, 2001).

The various conservation techniques can be described under the headings of agronomic measures, soil management and mechanical methods. Agronomic measures utilize the role of vegetation to protect the soil against erosion. Soil management is concerned with ways of preparing the soil to promote plant growth and improve its structure so that it is more resistant to erosion. Mechanical or physical methods, often involving engineering structures, depend on manipulating the surface topography - for example, installing terraces or windbreaks - to control the flow of water and air (Aklilu and Jan, 2004).

Agronomic measures combined with good soil management can influence both the detachment and transport phases of erosion, whereas mechanical methods are effective in controlling the transport phase but do little to prevent soil detachment. Preference is always given to agronomic measures (Yohanes, 1994). These are less expensive and deal directly with reducing raindrop impact, increasing infiltration, reducing runoff volume and decreasing wind and water velocities. They are more easily fitted into existing farming systems and more relevant to maintaining or restoring biodiversity, plant communities (Ibid, 1994).

Mechanical measures are largely ineffective on their own because they cannot prevent the detachment of soil particles. Their main role is in supplementing agronomic measures, being used to control the flow of any excess water and wind that may arise. Many mechanical works are costly to install and maintain. Some, such as terraces, create difficulties for farmers. Unless the soils are deep, terrace construction exposes the less fertile subsoils and may therefore result in lower crop yields (John et.al, 2003). On irregular slopes, terraces will vary in width, making for inefficient use of farm machinery, and only where slopes are straight in plan can this problem be overcome with parallel terrace layouts. Moreover, there is a risk of terrace failure in severe storms. When this occurs, the sudden release of water pounded up on the hillside can do more damage than if no terraces had been constructed. For all these reasons, terracing has been often unpopular with farmers (Ibid, 2003).

\section{Soil Problems, Protection Mechanisms and the Practice in Amhara Region \\ 3.1 Problems Related to Soil}

Among developing countries, Ethiopia can be a good example where such depletion of the soil resources is enormous. Dominated by small-scale agricultural producers, Ethiopia is one of the most severely eroded countries in the world. Ethiopian agriculture is characterized by extremely low productivity. Studies indicate that the national average yields of major crops for small holder sector are less than 1.2 metric tons per hectare. These yields are among the lowest in the world and indicate the low productivity of the agricultural sector, hence, the sector is not able to meet the basic food requirements of the population (Abera, 2003).

The ANRS, is highly devastated by this problem among other regions in the country. Especially in the eastern part of Amhara region, the factors that declining agricultural productivity, is the shortage of rainfall. It is the 
principal contributing factor to the low and that declining agricultural productivity in the region, the major one is low soil fertility due to excessive degradation of soils (Ibid, 2003).

Its manifestations are detected by the decline of crop yields; decline of water and forest resources and by gully formation across the grazing and ploughing fields. The eastern part of the region most of the time produce low productivity because it has been ascribed mainly due to land degradation and superabundant of soil loss through water erosion (Lakew, 2005). Because of this widespread problem, attracted the attention of the national as well as regional government to establish soil conserving mechanisms and different soil conserving proclamations.

\subsection{The Legal Ground on Soil Protection System}

The first comprehensive statement of Environmental Policy for the FDRE, was approved by the Council of Ministers in April, 1997. It was based on the policy and strategy findings and recommendations contained in the Conservation Strategy for Ethiopia (EPA, 2003). The Environmental Policy is predicated on a growing concern for the degradation of the natural resource base, and takes into account how that base is affected by, and affects, the overall productivity of the agriculture sector in the country (Ibid, 2003).

The overall policy goal is to improve and enhance the health and quality of life of all Ethiopians and to promote sustainable social and economic development through the sound management and use of natural, humanmade and cultural resources. The environment as a whole so as to meet the needs of the present generation without compromising the ability of future generations to meet their own needs (Ministry of agriculture and rural development, 2009).

Therefore, given the current stage of the country's political and policy development, the time is opportune for developing a comprehensive environmental policy on natural resources and the environment. It is clearly indicated that the wise use and systematic management of natural resources is a base to increase production and productivity of the agriculture sector and sustain development (Ibid, 2009)

It is Cleary indicated that the economic policy of current Ethiopian government is agricultural led industrialized economic strategy. The policy issues, foster uninterrupted and continuing access to the same land and natural resources on the part of farmers. In addition, it promotes the use of appropriate organic matter and nutrient management for improving soil structure, nutrient status and microbiology in improving soil conservation (Article 40 [3] of FDRE, 1995).

The rural land administration and land use proclamation No.456/2005 clearly indicated that, the right to ownership of land is exclusively vested in the state and in the people at large. According to this overall guiding rule, it has become necessary to conserve and develop natural resources in a sustainable manner and pass over to the coming generation through proper land use planning and management (Proclamation No.456 of FDRE, 2005).

Based on and the FDRE rural land administration and use proclamation the revised ANRS rural land administration and use proclamation No. 133/2006 give emphasis on conservation and imposes an obligation on farmers, among other things, to take necessary conservation measures in areas where there is a threat of soil erosion (Proclamation No. 133 of ANRS, 2006).

The Amhara National Regional State of the NRM strategy has been designed by dividing the region into two dichotomies: moisture deficit and moisture sufficient areas. In moisture deficit areas the policy gives attention on environmental rehabilitation practices and water catchment activities to avert the soil degradation problems and ultimately to make the preserved areas as a source of income generation for the local community. In moisture sufficient areas on the other hand the policy emphasis soil conservation mechanisms so that soil fertility can be maintained (Article 11 (7) of ANRS Regulation No.51/2007).

Dr. Demeke the vice head of the ANRS Agricultural Bureau advocated that, the purpose of sound management policy is to maintain the fertility and structure of the soil, in both the moisture deficit and moisture sufficient areas came into effect means of biological conservation or physical conservation. That is why, to achieve these goals, the regional executive members formulated these policies, not only based on the practical problem on the ground, but also based on the informed consent of the senior experts and model farmers on the issues at large (Interview with Dr. Demeke, 2015).

But, the three interviewed experts of Agricultural bureau and Land Administration and Environmental Protection and Utilization Bureaus criticized the government in that, before the policy formulation or at the times of policy formulation, the two bureau experts are not participating and commenting the proposal of these policies except any directors who are members of the party (All the interviewees experts, 2015).

\subsection{Practical Application of Soil Conservation Mechanism}

In Amhara Region proper use and management of agricultural land implies improving land productivity through encouraging different conservation and rehabilitation mechanisms and rational utilization of land resources (Abera et.al, 2012). In doing so, the regional NRM approach is community based integrated watershed development, taking participatory methods and watershed as a planning unit. 
As I interviewed, Dr. Demeke the vice head of the ANRS Agricultural Bureau, said that, the best mechanism to mobilize the people in ' water shad area' is based on building Development Army/DA. It means an integral part of the government (with its supply machinery), the ruling party (with its guidance) and the population at large (with their labor force), to conserve the soil in a selected watershed area. Based on this strategy, the community based participatory integrated watershed development, has been implemented for the last consequent five years (Interview with Dr. Demeke, 2015).

To achieve community based participatory activity in a watershed area; he listed, three different approaches or steps that have been used. These, are the preparation, implementation and evaluation phases.

\subsubsection{Preparation Phase}

At regional level, before the beginning of the activities through public mobilization, different preparatory works have been conducted. The first groundwork of this phase is selection of area and institutional arrangement process. Area selection is an activity in which a degraded land selected as a watershed area. It may be selected at kebele or district level by community participation (Ibid, 2015).

Furthermore, regards to an institutional arrangement, Ato Melese, Land Administration and Soil Protection Study Expert expressed that, the institutional arrangement is identification of the workforce in both sexes whose age is above 18 to be engaged in the watershed activity of a given locality. The work force is arranged in different institutional arrangements. One of these arrangements is Developmental Groups/ DG consisting 20 to 30 households are used to distribute every extension service to the community. The tasks of developmental group are: identification of the active labor force; give up and capture of daily share of work to and from the 1:5 work teams; reporting and evaluating of the daily work; and participate in the quality control activities (Interview with Ato Melese, 2015).

The second work force is 'one to five work team' are the lower level actors and organized based on nearness. It is formed by 'four or five' involved households who are members of the developmental group having one leader. Its formations enhanced equal share of work among the members, easily introduce quality control mechanisms, facilitate competitive motivation, build sense of individual responsibility, and reinforce effective collective action towards achieving common goals. The other arrangement is, 'rural command post' consists of the different institutional leaders and organized at different levels (Region, Zone and Woreda) are responsible for the supervision, control and oversight the overall rural development activities (Ibid, 2015).

The second groundwork of this phase is training Process. The level of training takes away from the region to villages. The issue of the training, giving to different modality is mainly focused on attitude, skill, organization, supply and arts of leadership. The first modality of training is given to political leaders, then, for expertise and the public at large (ANRS Report, 2005).

The third groundwork of this phase is planning process. It starts from top and cascaded down to the lower planning units through consultative and functional participatory tactic because, as it is claimed by higher level planners, at lower level there is low capacity and lack of resources inventory or database for reliable long term planning. In doing so, based on the higher level plan, each kebeles (local units) prepared its own plan in a watershed area or in individual level (Ibid, 2005).

\subsubsection{Implementation Phase}

In the implementation phase, the working force in a mobilized manner launched the campaign in a ceremonial manner through the region in a similar period of time. The work forces in their institutional arrangement come into the watershed area to meet their plan in an integrated manner (Lakew. et.al, 2005). The ultimate objective is to solve soil problems by adopting suitable protection measures in physical (contour bunds, terraces, ditches and cutoff drainages, check dam construction along waterways and gullies, tillage practices) and biological (area closure, vegetation-crops and crop residues) soil conservation mechanisms (Ibid, 2005).

In line with this, Dr. Demeke, said that: Before five years back considerable changes in the approaches used to promote and implement soil conservation were not developed at a community level as well as individual level. Perhaps the most fundamental changes have been coming in the last five years with community participatory development. At present based on building development army, the community mobilization strategies were effective in motivating collective action and involving all active labor forces (elders, women, men and youths) expected to participate in watershed development activities as per the plan (Interview with Dr. Demeke, 2015).

In the times of interview, again, he explained that, the community mobilization arrangements have allowed all to play their parts according to their ability. The active work forces both men and women were engaged in physical hard work (digging, excavation, stone transport) while the elders look after the children and the animals as well as they scout villages to protect from theft. Likewise women's participation showed good improvement, unlike the previous year's experience (Ibid, 2015).

In the same token, Mr. Aytenew Endeshaw, Natural Resource Development Conservation and Use Process Owner explained that: because of awareness creation in advance to the community, brings an unprecedented change in the conservation of soil and water in the watershed area. Physical activities such as hill side terraces, 
terraces maintenance and farm land terrace about 512 million people organized as DG and one to five arrangements conserved 2,986,329 hectares degraded land in the last three years (Interview with Ato Aytenew, 2015).

Again he enumerated that, in the above period of time, community based participatory activity have been constructed 801,469 hectare check dams on waterways with erosion risk, on footpaths and in gullies. They try to quantify the sediment retained by the check dams after every rainstorm in order to become more aware of soil and nutrient loss from farm plots. Incorporating periodic sediment monitoring is thus an improvement in the practice of building check dams (Ibid, 2015).

Most of the time, the work volume was allocated to 1:5 work team based on the number of members while the work was done in a team in most cases. But there was a division of labor within the working team where women mainly involved in soil mine, soil bund compaction, transporting stones, and sometimes paving the waterways while the men engaged in digging trenches and ditches, construction of stone terraces, waterways, and cut off drains (Abera, 2012).

Regards to this, Mr. Aytenew Endeshaw, as a Natural Resource Development Conservation and Use Process Owner illustrated that, the activity performed based on community participatory in the water shade area as well as in the farm plot area in the last tree consequent years are demonstrated in the table below.

\begin{tabular}{|l|l|r|r|r|r|}
\hline Activity & Unit & 2012 year & 2013 year & 2014 year & Total \\
\hline Steep slope area closure & ha & 425,818 & 267,920 & 267,256 & 960,994 \\
\hline Hill side terrace & ha & 116,619 & 147,876 & 139,990 & 404,485 \\
\hline Moisture Harvesting Str & $\mathrm{m} /$ no & 54 & 50 & 26.4 & 130.4 \\
\hline Farm land Terrece & ha & 458,508 & 621,849 & 630,909 & $1,711,266$ \\
\hline Terrace Maintenance & ha & 299,060 & 339,383 & 232,135 & 870,578 \\
\hline Bio. Cons. On terraces & ha & 175,211 & 481,391 & 144,867 & 801,469 \\
\hline Drainage stru. & $\mathrm{km}$ & 16,002 & 19,827 & 14,606 & 50,435 \\
\hline Seedling raising & $\mathrm{B} /$ no & 1.53 & 1.7 & 1.975 & 5.205 \\
\hline Seedling Planting & $\mathrm{B} /$ no & 1.1 & 1.3 & 1.62 & 4.02 \\
\hline Area planted & ha & 155330 & 224647 & 317,677 & 697,654 \\
\hline Gully Rehabilitation & ha & 6,044 & 18,953 & 9,971 & 34,968 \\
\hline Participants Persons/Day & & $107,462,718$ & 198780707 & $205,725,960$ & $511,969,385$ \\
\hline
\end{tabular}

The above mentioned and other physical structures are essential to improve degraded land, to control runoff water and contribute in recharge of water tables and ultimately soil fertility can be maintained and around 3.83 million hectare of land has been covered by watershed activities. This is an indicator that the issue of soil conservation has got more attention (Interview with Ato Aytenew, 2015).

Moreover, Ato Melese regards to physical works noted that, it is made by the integrated watershed activities cannot be sustainable unless they are supported by biological matters. Area closure becomes more effective where it is combined with different soil and moisture conservation measures because it restores sufficient productivity for the growth of trees, grasses and other species. In the last four years [2012, 2013 and 2014] in the ANRS around 960,994 hectares of plot of land is kept under area closure (Interview with Ato Melese, 2015)

Similarly, Mr. Aytenew elaborated again and again; the physical activity without biological activity is working without effect. That is why the biological activity which applies in watershed areas or an individual farm land has immense benefit to our eco-system. The example in the last three years, 500,000 hectares of land has been covered by multipurpose plants and grasses annually (Ibid, 2015).

In the same manner, as Ato. Getachew Alamrew, who works for BoLAEPU as Environmental Resource Evaluation and Study Expert said that; because of an increased awareness of the rural community or farmers in conserving the watershed area, the forest coverage of the region shows some incremental change, that is before five years the forest coverage of the region was $5.5 \%$, but currently it is estimated at around $11.3 \%$. In doing so, it protects around 960,000 hectares of eroded plot of land in the Region starts to rehabilitate. This by itself reduced the amount of soil to be eroded which could be transported by erosion and now the water shade area serve as an economic means of the rural youth, for irrigation activity, it produces animal feed like Lusatia and ligaments (Interview with Ato Getachew, 2015).

The command posts assumed strict control and follows up in order to get effective and efficient work performance, during the time of implementation requires, it may be at the regional, zonal, woreda and at kebele level. But, the command post, go after day to day activities in the developed groups has varied from place to place, based on the strength of the leaders (Ibid, 2015).

On the other hand, all respondents assured that, though there is a tremendous change or awareness emerge in conservation of our environment, there are also hindrances that cover the face of some farmers, to conserve and protect their endowment of natural recourses; that is culturally they assume that accepting the new technology seams hurt their land, leave their cutlets in some protected watershed area, they frequently overgrazed a particular area, some of them cannot performed the physical activities even if their land is eroded (All the interviewees, 2015). 
Because the government had not worked in advance about the usefulness of the policy and its future benefit on the parts of the community. Plus, the community is working in the watershed areas through force and harassment and anti-democratic approach. If no force by the local government, they should not participate in the watershed area due to lack of awareness and consciousness between the government and the people. Again, they expressed that, rather than the community; our experts have not participated in the policy formulation process. Even in practice, there is no functional linkage between Agricultural bureau and Land Administration and Environmental protection and utilization bureau. All these factors are a hindrance to sustainable watershed development (Ibid).

They also expressed the shortage of regional government as well; one of the factors of loss of soil is deforestation, in doing so, the rural population cut trees unwisely as a repeated practice. In this manner even if there is a forest proclamation in the country, at regional level, there is no a forest proclamation or enforcing law. Because of these the farmers leave their scuttles where ever in protected areas. Similarly, there is also a shortage of continuous supervision and controlling mechanism on the watershed area and on plants trees; there is also a shortage of scale up on best practices and shortage of creation awareness on those farmers on the part of the government (Ibid).

The other problem is, though the government planned to use the various conservation techniques such as agronomic measures, soil management and mechanical methods, but the aggregate effort of the government is focusing on mechanical methods. The government even trying to apply, the biological methods, especially in the summer program, after the trees have planted, nobody has followed and cultivated it. That means the major objective of the government is remained in the means rather than ends (All the interviewees, 2015).

\subsubsection{Evaluation Phase}

Evaluation is a last phase that took place to assess the activity at each level of government to accomplish the campaign. The evaluation at all levels; the watershed case team should take this responsibility and develop comprehensive post monitoring and evaluation system with the watershed development committee (Abera et.al, 2012).

As Ato Aytenew elaborated it, at the end of the evaluation the amount of watershed activities performed in that budget year clearly identified, challenges faced during implementation period sorted out, best practices acquired will be well organized to apply in the coming budget year, and best performers as well as least performers at individual as well as organization level will be identified (Interview with Ato Aytenew, 2015). Again he summarized that, all the identified activities are used for the next budget year annual plan as a precondition analysis at individual as well as organization plan.

\subsection{Conclusion and Recommendation}

In Ethiopia soil degradation is prevalent at a disastrous rate. The average annual rate of soil loss in the country is estimated to be 12 tons/hectare/year, and it can be even higher on steep slopes and on places where the vegetation cover is low. Similarly, in Amhara National Regional State, the problem is more solemn. By taking this problem into account, starting on wards from 2008, the regional government gives due attention and do a remarkable watershed activity accordingly.

The mechanisms to adopt soil conservation practices, particularly in the integrated watershed areas, the government arranged different parts of the society into three pillars of Developmental Army groups. That mobilized towards this campaign with a systematic institutional arrangement. Important institutional arrangements and tactics which have been taken in watershed areas throughout the region. In doing so, throughout the past five years, some advancement has been achieved in the soil protection system.

But, the problem is aggravating parallel to the emerging changes. Because, on the one hand, the government has not designed efficient and effective monitoring and evaluation mechanism rather than the traditional evaluation method, on the other hand, even if the already established rules are recommendable, the practical application on the ground is paradoxical to the rule on paper. The other limitation is lack of commitment to its implementation, on the parts of government and lack of awareness on the parts of the community.

All the results under this study are potential areas for undertaking further research. Nevertheless, as a matter of main concern, research on the following areas is recommended: First, in order to ensure efficiency and effectiveness of the organizational arrangements, the regional government should be established a systematic and continuous monitoring and evaluating system that should be promote a decision and solution maker and not dependent on leadership personalities.

Second for sustainable soil conservation program an effective and legal forest protection proclamation, laws relating to land use planning, forest management, species and habitat protection and water management will be established in the region. Plus, the government should give attention on biological work, because area closure becomes more effective where it is combined with different soil and moisture conservation measures because it restores sufficient productivity for the growth of trees, grasses and other species. 
Third, continuous awareness creation will be strengthened on the farmers that think the land as their own life., the problem related to implementation processes will be the focus area of the government. Finally, there is no functional linkage between Agricultural bureau and Land Administration and Environmental protection and utilization bureau. Efforts must be made in the realization of this linkage, including revising the law to clearly set up a practical institutional linkage between the two sectors to protect soil erosion in the ANRS.

\section{Reference Book}

Abate Shiferaw. (2011). Estimating Soil Loss Rates for Soil Conservation Planning in the Borena Woreda of South Wollo Highlands, Amhara Region: Ethiopia.

Abay Ayalew. (2011). Construction of Soil Conservation Structures for Improvement of Crops and Soil Productivity in the Southern Ethiopia.

Abera B. (2003). Factors Influencing the Adoption of Soil Conservation Practices in the North Western Ethiopia.

Abera Wondafrash, Belayneh Ayele and etal. (2012). Assessment of Natural Resources Management Works through Public Mobilization in Amhara National Regional State, BahirDar: Ethiopia.

Aklilu Amsalu and Jan de Graaff. (2004). Farmers Views of Soil Erosion Problems and Their Conservation Knowledge at Beressa Watershed, Central Highlands of Ethiopia.

Amhara National Regional. (2005). Annual Report State Bureau of Agriculture, Bahirdar: Ethiopia

ANRS Rural Land Administration and Use Proclamation, Proclamation No. 133/2006. Bahir Dar: Ethiopia.

ANRS Rural Land Administration and Use System Implementation, Council of Regional Government Regulation, Regulation No.51/2007, Article 11(7), Bahir Dar:Ethiopia.

Bekele, S and Holden, S.T. (1998). Resource Degradation and Adoption of Land Conservation Technologies in the Ethiopian Highlands: A Case Study in Andit Tid, North Shewa, Agricultural Economics.

Dessalegne Mesfin. (2007). Evolution of the Environmental Impact Assessment System of Ethiopia

Edward. L. Skidmore and Simon J.(1987). Soil Erosion and Conservation, Hand Kook of Processes and Modeling in Soil-plant System.

Environmental Protection Authority/EPA.(2003).The Federal Democratic Republic of Ethiopia-State of Environment Report for Ethiopia. Addis Ababa: Ethiopia.

FDRE Rural Land Administration and Land Use Proclamation, Proclamation 456/2005.

FDRE Ministry of Agriculture and Rural Development (2005).A Guide Line, Community Based Participatory Watershed Development, Addis Ababa: Ethiopia.

Federal Democratic Republic of Ethiopia [FDRE] (1995). The Constitution of the Federal Democratic Republic of Ethiopia, article 40, Federal Negarit Gazeta 1/1, Addis Ababa.

Gizaw Desta and Hans Hurni. (2011). Farmers' Participatory Soil Erosion Assessment and Soil Conservation Improvement. Application of Local Erosion Indicators, Amhara Regional Agricultural Research Institute (ARARI), Ethiopia, and Centre for Development and Environment (CDE), University of Bern.

Hurni, H. (1986). Guideline for Development Agents on Soil Conservation in Ethiopia, CFSCDD, MOA, Addis Ababa: Ethiopia.

International Atomic Energy Agency. (2001). Impact of Soil Conservation Measures on Erosion Control and Soil Quality, Vienna: Austria.

John Boardman, Jean Poesen and Robert Evans. (2003).Socio-Economic Factors in Soil Erosion and Conservation,

Lakew Desta, Carucci, V., Asrat Wendem-Agegnehu and Yitayew Abebe (eds). (2005). Community Based Participatory Watershed Development: A Guideline (Part 1 and Part 2), Ministry of Agriculture and Rural Development (MOARD), Addis Ababa: Ethiopia.

Ministry of Agriculture and Rural Development. (2009). Food Security Program; 2010-2014. Addis Ababa: Ethiopia

Morgan RPC. 3rd ed. (2005). Soil Erosion and Conservation. National Soil Resources Institute, Cranfield University, Blackwell: Malden.

Philippe Sands. (2 ${ }^{\text {nd }}$ ed). (2003). Principles of International Environmental Law, United States of America , Cambridge University Press: New York

Tor, Benjaminsen. (1997). Natural Resource Management, Paradigm Shifts, and the Decentralization Reform in Mali.

Yohanes, G.(1994).Watershed and Household Level Approach in the Analysis of the Sustainability of Introduced Physical SWC Measures in Ethiopia.Presented at 8th International Soil Conservation Conference: India.

\section{List of Interviews}

Interview with Ato Aytenew Endeshaw, Natural Resource Development Conservation and Utilization Process Owner of Agricultural Bureau, Bahirdar City, March 20, 2015.

Interview with Dr. Demeke Atilaw, A Vice Head of Agricultural Bureau of ANRS, Bahirdar City, March 20, 2015. 
Interview with Ato Getachew Alamrew, Environmental Resource Evaluation and Study Expert of BoEPLAU, Bahir Dar, March 28, 2015.

Interview with Ato Melese, Abate-, Land Administration and Soil Protection Study Expert of BoEPLAU, Bahir Dar, March 28, 2015. 